\section{Sciensage}

Journal of Advanced Scientific Research

Available online through https: / /sciensage.info
ISSN: 0976-9595

Research Article

DOI: $10.55218 /$ JASR. 202213138

\title{
DEVELOPMENT OF TRIAZINE BASED DENDRIMER OF SALICYLIC ACID WITH INCREASED ANTIBACTERIAL ACTIVITY
}

\author{
Megha Joshi*, Kamlesh Dashora \\ Institute of Pharmacy, Vikram University Ujjain, Madhya Pradesh, India \\ *Corresponding author: meghajoshi2486@gmail.com
}

\begin{abstract}
The aim of this research work was to develop triazine based dendrimer of salicylic acid with increased antibacterial activity. Surface modification of dendrimer of generation 3 was performed by conjugation with polyethylene glycol (PEG). The amount of drug encapsulated in dendrimer was determined by the separation of drug loaded dendrimer from the suspension containing free drug by centrifugation. The suspension obtained after solvent evaporation was centrifuged. The amount of free drug in the supernatant was measured by UV spectrophotometer. The amount of drug entrapped into dendrimer was calculated as the difference between the drug used for formulation and the amount of drug in supernatant. Antibacterial activity shows promising results as prepared dendrimer drug conjugate shows better results with only $36.05 \%$ entrapped drug as compared to standard drug. $36.05 \%$ entrapped drug gives results more than as compared to standard drug sample. Results reveals that if we assume that the standard drug is completely entrapped, there will be approximately 2.5 fold increase in antibacterial activity. This study also reveals that salicylic acid and prepared dendrimer drug conjugates show better activity for $S$. aureus i.e. for gram positive bacteria.
\end{abstract}

Keywords: Dendrimers, Triazine dendrimer, Synthesis, Salicylic acid, Antibacterial activity.

\section{INTRODUCTION}

In 1929, some scientist tried to synthesize polymers in laboratory with some definite structure. The presence of polymers was unavoidable around 1930s [1-3]. For next 20 years researches in polymer chemistry had increased and many novel contributions were added to science and society with the creations of new materials. The ability and desire to manipulate the architecture of macromolecules was now the subject of research. At the time, networked and cross-linked polymers were identified, but most of them resulted in random branching. New classes of polymeric molecular structure are Dendrimers [4-8]. Dendrimers are monomolecular and discrete structures with known composition and atomic connectivity developed from a class of synthetic macromolecules that allowed for the regulated assembly of large assemblies of atoms. Many natural things have three-dimensional architectural molecular symmetrical structures which are highly regular and in nano size. These symmetrical threedimensional structures, especially macromolecules, could be used as building blocks for molecular devices and nanotechnologies [9]. These words refer to "dendritic macromolecules", which are currently one of the most intensively researched new materials due to their most intriguing special features and characteristics. As scientists explore the interesting characteristics of atomic and molecular constructions developed at the nanometer scale, nanotechnology is becoming one of the most important research efforts of the early twentyfirst century. Researchers can sanely design and use nanoparticles for drug delivery, as image contrast agents, and for diagnostic purposes because they can control their physical, chemical, and biological properties [10].

The Greek word "Dendrimer" which means dendrons that is like a tree and meros means units or parts. This shows that dendrimers are tree like in growth, appearance and structure. These structures have at least one branched junction at each repeat unit [11-15] and are considered to be monodisperse macromolecule with perfectly branched regular structure. Here, all chain ends originate from a central core and all repeating unit constitute a branch point. Thus, dendrimers are new class of three-dimensional regular structural macromolecule produced by various synthetic routes. Dendritic polymers are nanometer-sized (10-9 m) spherical type molecules. Dendrimers are formed by 
iterative sequence of different reaction steps, each additional iteration leads to high generation dendrimer. These unique structures can be utilized as a tool for desired functions such as internal voids, well defined shape and variable surface functionality. Dendrimer possess many other names such as "starburst dendrimere", "cascade molecules"e, "arborols" scaffolds" and "dendritic polymers" [15-20].

With the advancement of new technologies and techniques these drawbacks can be overcame and drugs may be used purposely. One such technique is nanoscale dendrimers. One such established drug is salicylic acid which has been less used systemically due to some toxicity issues of mucosal lining and gastrointestinal tract. But due to its multiple beneficial effects, the drug now is used for local application for acne, eczema, dermatitis, fungal infection and as keratolytic agent [21-24].

We have synthesized a novel surface modified triazine based dendritic molecule of salicylic acid; the wonder drug" using divergent method. Dendrimer was synthesized up to three generation, surface modified with polyethylene glycol and loaded with salicylic acid. The synthesized compound were characterized and tested for biological activity [25-28].

\section{MATERIAL AND METHODS}

Triazine trichloride, 1,3 Propane di-amine, Dichloromethane, Epichlorhydrin and Diethanolamine, were received as gift samples from Shree ji Trade International, Indore. Acetone, methanol, ethanol, salicylic acid, EDA, PEG 200 and all other reagents and solvents, chemicals and equipments used for synthesis and analysis were provided by the Institute of Pharmacy, Vikram University, Ujjain. UV spectroscopy was performed on shimadzu 1800, FTIR studies was performed on shimadzu 8400, mass spectroscopy was performed on Waters Micromass Q-Tof Micro. ${ }^{1} \mathrm{H}$ NMR was performed on Avance-II (Bruker) spectrophotometer. SEM was performed on JSM 6100 (JEOL).

\subsection{General procedure for synthesis of Generation 0.5 dendrimer}

Cyanuric Chloride $(0.04 \mathrm{mmol})$ was dissolved in dichloromethane and kept in an ice bath. A solution of a 1,3 propane diamine $(0.02 \mathrm{mmol})$ dissolved in sodium hydroxide $(0.04 \mathrm{mmol})$ in water was added drop wise in the solution of cyanuric chloride at $0-5^{\circ} \mathrm{C}$ with stirring.
The solution was stirred at $0-5^{\circ} \mathrm{C}$ for $2 \mathrm{hrs}$. Then the solution was filtered, washed with methanol and acetone. Remnants were dried under vacuum. A white coloured solid was obtained. Progress of reaction was monitored through TLC.

\subsection{General procedure for synthesis of Generation 1 Dendrimer}

G 0.5 dendrimer $(0.02 \mathrm{mmol})$ was dissolved in an excess of diethanolamine $(0.08 \mathrm{mmol})$ which was used as both solvent and reactant. The resulting mixture was refluxed for 2 hrs. After cooling, it was washed by acetone repeatedly to give generation 1 dendrimer. Dendrimer obtained was light brown coloured with honey like consistency.

\subsection{General procedure for synthesis of Generation 1.5 Dendrimer}

Cyanuric chloride $(0.08 \mathrm{mmol})$ was dissolved in dichloromethane and kept in an ice bath. A solution of G1 dendrimer $(0.01 \mathrm{mmol})$ containing sodium hydroxide $(0.08 \mathrm{mmol})$ in water was added drop wise in the solution of cyanuric chloride at $0-5^{\circ} \mathrm{C}$ with stirring. The solution was stirred at $0-5^{\circ} \mathrm{C}$ for $2 \mathrm{hrs}$ and refluxed for 6 hrs. Then the solution was filtered, washed with methanol and acetone and dried under vacuum. A white coloured solid was formed.

\subsection{General procedure for synthesis of Generation 2 Dendrimer}

Generation 1.5 dendrimer $(0.01 \mathrm{mmol})$ was dissolved in an excess of diethanolamine $(0.16 \mathrm{mmol})$ which was used as both solvent and reactant. The resulting mixture was refluxed for $2 \mathrm{hrs}$. After cooling, it was dispersed and washed by acetone repeatedly to give generation 2 dendrimer which was light brown coloured with honey like consistency.

\subsection{General procedure for synthesis of Generation 2.5 Dendrimer}

Cyanuric Chloride $(0.32 \mathrm{mmol})$ was dissolved in dichloromethane and kept in an ice bath. A solution of G2 dendrimer $(0.01 \mathrm{mmol})$ containing sodium hydroxide $(0.32 \mathrm{mmol})$ in water was added dropwise in the solution of cyanuric chloride at $0-5^{\circ} \mathrm{C}$ with stirring . The solution was stirred at $0-5^{\circ} \mathrm{C}$ for $2 \mathrm{hrs}$ and refluxed for $6 \mathrm{hrs}$. The solution was then filtered, washed with methanol and acetone and dried under vacuum. A white coloured solid was formed. 


\subsection{General procedure for synthesis of Generation 3 dendrimer}

Generation 2.5 dendrimer $(0.01 \mathrm{mmol})$ was dissolved in an excess of diethanolamine $(0.64 \mathrm{mmol})$ which was used as both solvent and reactant. The resulting mixture was refluxed for $2 \mathrm{hrs}$. After cooling, it was dispersed and washed by acetone repeatedly to give generation 3 dendrimer which was light brown coloured with honey like consistency.

\section{Reaction Scheme}

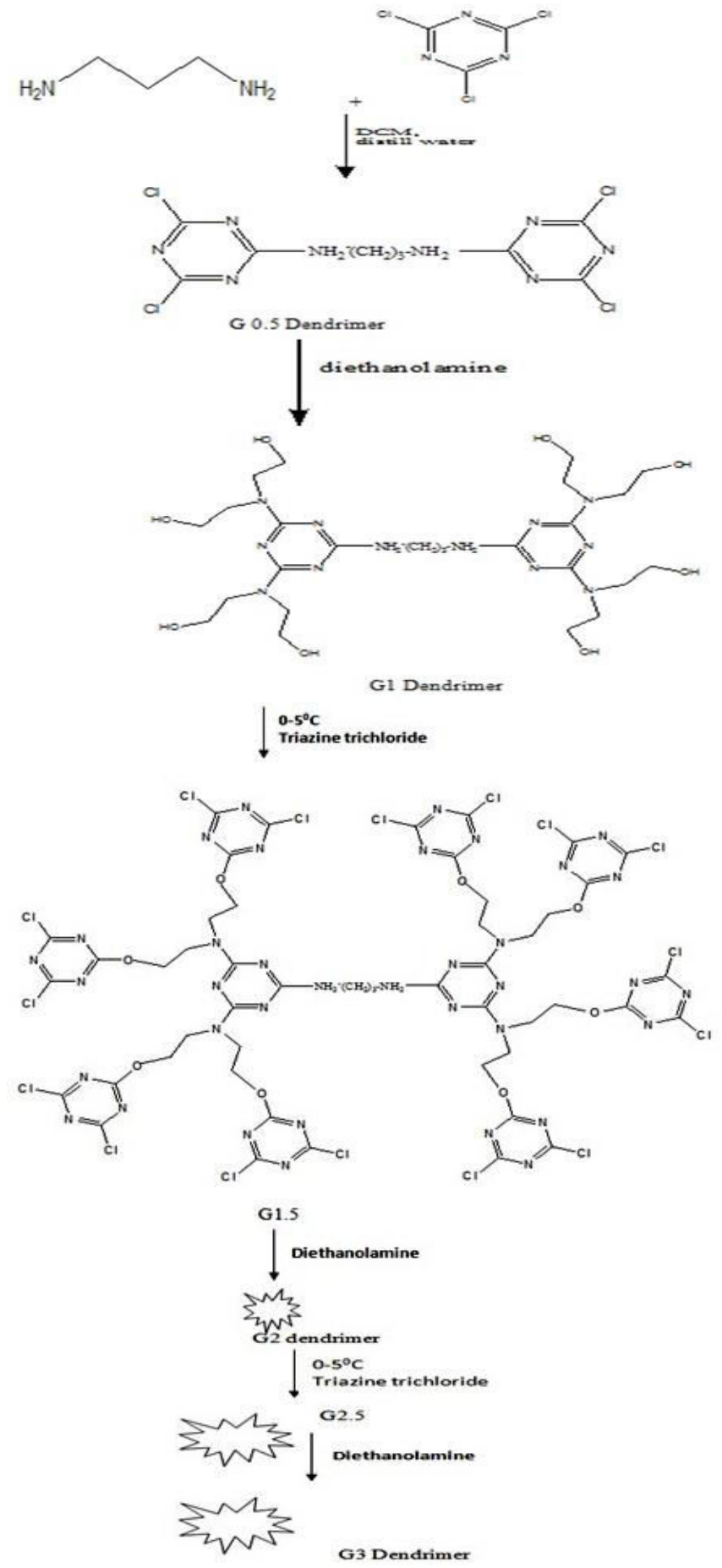

\section{RESULTS AND DISCUSSION}

Dendrimers were synthesized up to 3 generations and then modified with PEG. Surface modified dendrimer was then conjugated with salicylic acid.

\subsection{Characterization of Dendrimers \\ 3.1.1. Generation 0.5 dendrimer}

\%yield- $79 \%$, M.P- $145^{\circ} \mathrm{C}, \lambda_{\max }(\mathrm{nm})-277$ Major peaks $851,878-\mathrm{C}-\mathrm{Cl}$ stretching, $1617,1704-$ aromatic $\mathrm{C}=\mathrm{N}$, 2869- C-H Stretching, 3055- N-H Stretching.

\subsubsection{Generation 1 Dendrimer}

$\%$ yield- $68 \%$, M.P- $170^{\circ} \mathrm{C}, \lambda_{\max }(\mathrm{nm})-284$, FTIR Major peaks-1020- C-O stretching, 1710- aromatic $\mathrm{C}=\mathrm{N}$, 2950 C-H Stretching, 3372- OH stretching.

\subsubsection{Generation 1.5 Dendrimer}

\%yield- $77 \%$, M.P- $185^{\circ} \mathrm{C}, \lambda_{\max }(\mathrm{nm})-278$ FTIR Major peaks-784,793- C-Cl stretching, 1080- C-O stretching, 1697, 1734-aromatic C=N, 2841- C-H Stretching, 3181 - N-H Stretching.

\subsubsection{Generation 2 Dendrimer}

\%yield- $72 \%$, M.P- $205^{\circ} \mathrm{C}, \lambda_{\max }(\mathrm{nm})-282$ FTIR Major Peaks- 1045-C-O Stretching, 1648, 1741-aromatic $\mathrm{C}=\mathrm{N}, 3072$, 2943- C-H Stretching, 3354- OH stretching.

\subsubsection{Generation 2.5 Dendrimer}

\%yield- 74\%, M.P-220 ${ }^{\circ} \mathrm{C}, \lambda_{\max }(\mathrm{nm})-277$ FTIR Major Peaks 774- C-Cl stretching, 1039,1079- C-O Stretching, 1716- aromatic $\mathrm{C}=\mathrm{N}, 2890-\mathrm{C}-\mathrm{H}$ Stretching, 3074- N-H Stretching.

\subsubsection{Generation 3 dendrimer}

$\%$ yield- $62 \%$, M.P- $230^{\circ} \mathrm{C}, \lambda_{\max }(\mathrm{nm})-283$ FTIR major peaks 1051, 1082- C-O stretching, 1606, 1719aromatic C $=\mathrm{N}$ stretching,2917,3074 C-H Streching, 3396-OH stretching, calculated ESI mass 12044 obtained $12045, \delta$ values ppm ${ }^{1} \mathrm{HNMR}$ - 2.507 Amide$\mathrm{NH}, 3.264,3.49-\mathrm{CH}_{2} \mathrm{NH}_{2}$ terminal group, $4.70 \mathrm{OH}$ (methanolic).

\subsection{Surface Modification of Dendrimer}

Surface modification of dendrimer of generation 3 was performed by conjugation with polyethylene glycol (PEG). Polyethylene glycol of molecular weight 200 was used and EDA was used as cross linking agent. PEG (0.5 gm) was dissolved in water/ethanol $(1: 1,20 \mathrm{~mL})$ and EDA (0.43 gm) was dissolved in $20 \mathrm{~mL}$ water separately. Both the solutions were mixed with continuous stirring. 
3.0 Generation dendrimer $(1 \mathrm{gm})$ in $20 \mathrm{~mL}$ distilled water was added slowly to the reaction mixture with constant stirring in an ice bath for $30 \mathrm{~min}$. and stirring was continued for another 24 hours. Progress of the reaction was monitored through TLC.

$\%$ yield- $71 \%$, M.P- $280^{\circ} \mathrm{C}, \lambda_{\max }(\mathrm{nm})-279$ FTIR Major Peaks- 1061- C-O stretching, 1715- aromatic $\mathrm{C}=\mathrm{N}$ stretching, 2891- C-H Stretching, 3365- OH stretching $\delta$ values $\mathrm{ppm}^{1} \mathrm{HNMR}$ - 2.60 Amide -NH, 3.466,3.635$\mathrm{CH}_{2} \mathrm{NH}_{2}$ terminal group, $4.60 \mathrm{OH}$ (methanolic).

\subsection{Conjugation of surface modified dendrimer by with salicylic acid}

The incorporation of salicylic was carried out by dissolving $50 \mathrm{mg}$ of salicylic acid in $10 \mathrm{ml}$ methanol, $2 \mathrm{ml}$ of this solution was mixed with $50 \mathrm{mg}$ of $3.0 \mathrm{G}$ dendrimers. Both the solutions were mixed with continuous stirring in an ice bath for 30 min. stirring was continued for another 6 hours. Progress of the reaction was monitored through TLC. Drug conjugated modified dendrimer was taken out, washed with methanol and dried which gives light yellow colored product

$\%$ yield- $74 \%$, M.P- $300^{\circ} \mathrm{C}, \lambda_{\text {max }}(\mathrm{nm})-264$ FTIR Major Peaks- 1676- aromatic $\mathrm{C}=\mathrm{C}, 1716$ - aromatic $\mathrm{C}=\mathrm{N}$ stretching, 2552- ,2921- C-H Stretching, 3383- O-H stretching

\subsection{SEM Analysis}

To obtain a clear insight about the surface morphology of synthesized compound, Scanning Electron Microscopic (SEM) analysis was employed.

From SEM image, stone like morphology was observed. Surface of the particles are spherical and the particles exhibit very uniform and well distributed. This image shows clearly that the surface is composed of macro particle unit and drug was associated with this particle.

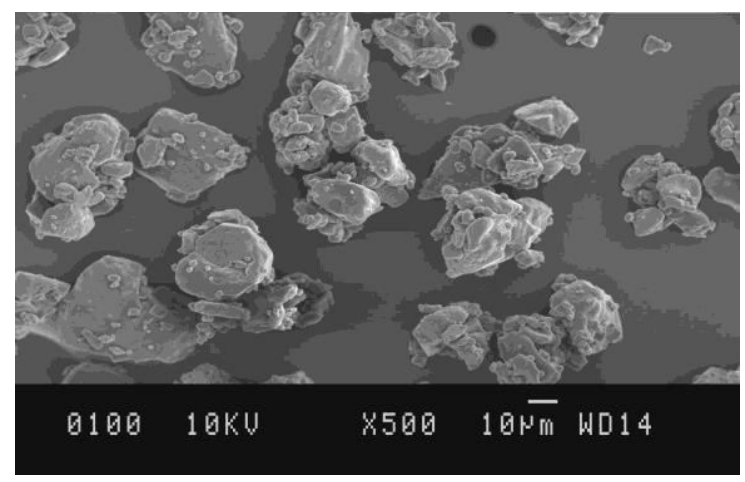

\footnotetext{
Fig. 1: SEM of prepared denndrimer drug conjugate
}

\subsection{Drug Entrapped Efficiency}

The amount of drug encapsulated in dendrimer was determined by the separation of drug loaded dendrimer from the suspension containing free drug by centrifugation. The suspension obtained after solvent evaporation was centrifuged. The amount of free drug in the supernatent was measured by UV spectrophotometer. The amount of drug entrapped into dendrimer was calculated as the difference between the drug used for formulation and the amount of drug in supernatent. The percent of entrapment efficiency was calculated by following formula.

$\%$ Entrapment Efficiency $=\{($ Total amount of drug added- Non bound drug)/Total amount of drug $\} \times 100$ Drug entrapment efficiency of PEG modified dendrimer and salicylic acid at $234 \mathrm{~nm}$ was found to be $36.05 \pm 0.5 \%$.

\subsection{Antibacterial activity}

Antibacterial activity of PEG modified dendrimer salicylic conjugate was tested on E. coli and S. aureus. The cylinder method was used to test antibacterial activity, the agar culture media was prepared, sterilized and transferred to a petridish and left to set. After setting up the culture media, two drops $(0.1 \mathrm{ml})$ of the sample solution were aseptically put into wells created by scooping out the media with a sterilised glass tube ( $5 \mathrm{~mm}$ diameter). These were then incubated for 24 hours at $37 \pm 1^{\circ} \mathrm{C}$. After that, the zone of inhibition was measured and compared to the standard.

For this study One gram positive (S. aureus, L27) and one gram negative (E. coli MC410) bacteria has been chosen for activity.

\subsubsection{Preparation of stock solution of standard drug}

The stock solution of salicylic acid $(1 \mathrm{mg} / \mathrm{ml})$ in $\mathrm{N}, \mathrm{N}$ dimethylformamide (DMF) was prepared by dissolving $10 \mathrm{mg}$ of the drug in $10 \mathrm{ml}$ DMF.

\subsubsection{Preparation of solutions of synthesized compounds}

The stock solution of each synthesized compound $(1 \mathrm{mg} / \mathrm{ml})$ in DMF were prepared by dissolving $10 \mathrm{mg}$ of the sample in $10 \mathrm{ml}$ DMF.

Antibacterial activity shows promising results as prepared dendrimer drug conjugate shows better results with only $36.05 \%$ entrapped drug as compared to standard drug. $36.05 \%$ entrapped drug gives results more than as compared to standard drug sample. 
Table 1: Zone of inhibition (in $\mathrm{mm}$ ) of standard drug and prepared dendrimer drug

\begin{tabular}{ccc}
\hline $\begin{array}{c}\text { Name of } \\
\text { bacteria }\end{array}$ & $\begin{array}{c}\text { standard } \\
\text { salicylic } \\
\text { Acid }\end{array}$ & $\begin{array}{c}\text { Prepared dendrimer } \\
\text { drug sample } \\
\mathbf{( 3 6 . 0 5 \% )}\end{array}$ \\
\hline E.coli & 4.60 & 5.00 \\
\hline S. Aureus & 10.20 & 10.30 \\
\hline
\end{tabular}

Table 2: Zone of inhibition in E.Coli

\begin{tabular}{ccc}
\hline Parameter & $\begin{array}{c}\text { Prepared drug } \\
\text { conjugate }\end{array}$ & Remarks \\
\hline $\begin{array}{c}\text { \% drug } \\
\text { entraped }\end{array}$ & $36.05 \%$ & $\begin{array}{c}\text { Approx 63\% } \\
\text { less drug used }\end{array}$ \\
\hline $\begin{array}{c}\text { Zone of } \\
\text { inhibition in } \\
\text { E.Coli (in } \mathrm{mm} \text { ) }\end{array}$ & $5.0 \mathrm{~mm}$ & $\begin{array}{c}\text { Approx. 2.5 } \\
\text { fold increase in } \\
\text { activity. }\end{array}$ \\
\hline
\end{tabular}

Table 3: Zone of inhibition in S. aureus

\begin{tabular}{ccc}
\hline Parameter & $\begin{array}{c}\text { Prepared drug } \\
\text { conjugate }\end{array}$ & Remarks \\
\hline$\%$ drug entrapped & $36.05 \%$ & $\begin{array}{c}64 \% \text { less } \\
\text { drug used }\end{array}$ \\
\hline $\begin{array}{c}\text { Zone of inhibition } \\
\text { in S. aureus (in } \\
\mathrm{mm} \text { ) }\end{array}$ & $10.3 \mathrm{~mm}$ & $\begin{array}{c}\text { Approx. } 2.5 \\
\text { fold increase } \\
\text { in activity. }\end{array}$ \\
\hline
\end{tabular}

This reveals that if we assume that the standard drug is completely entrapped, there will be approximately 2.5 fold increase in antibacterial activity. The study also reveals that salicylic acid and prepared dendrimer drug conjugates show better activity for $S$. aureus i.e. for gram positive bacteria.

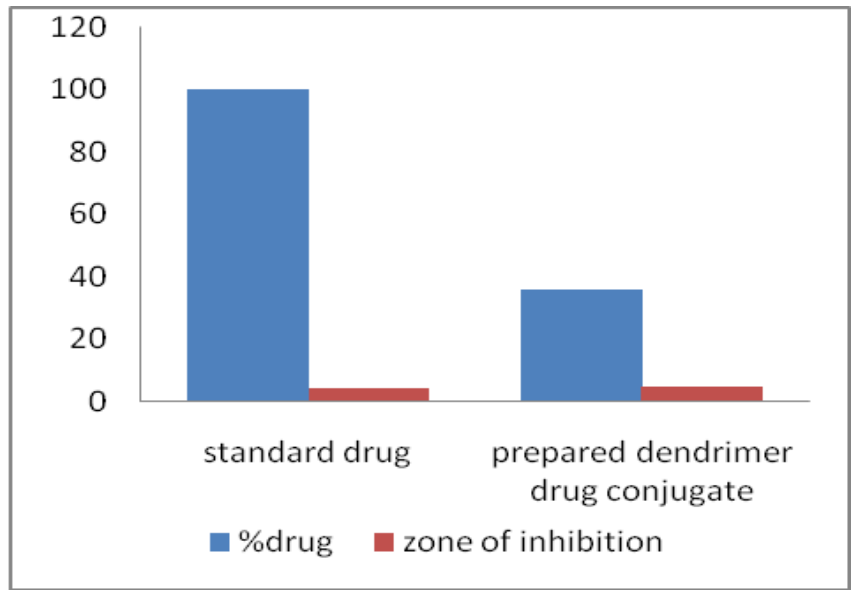

Fig. 2: Graph comparing standard drug and its zone of inhibition and prepared dendrimer drug conjugate and its zone of inhibition in E. coli

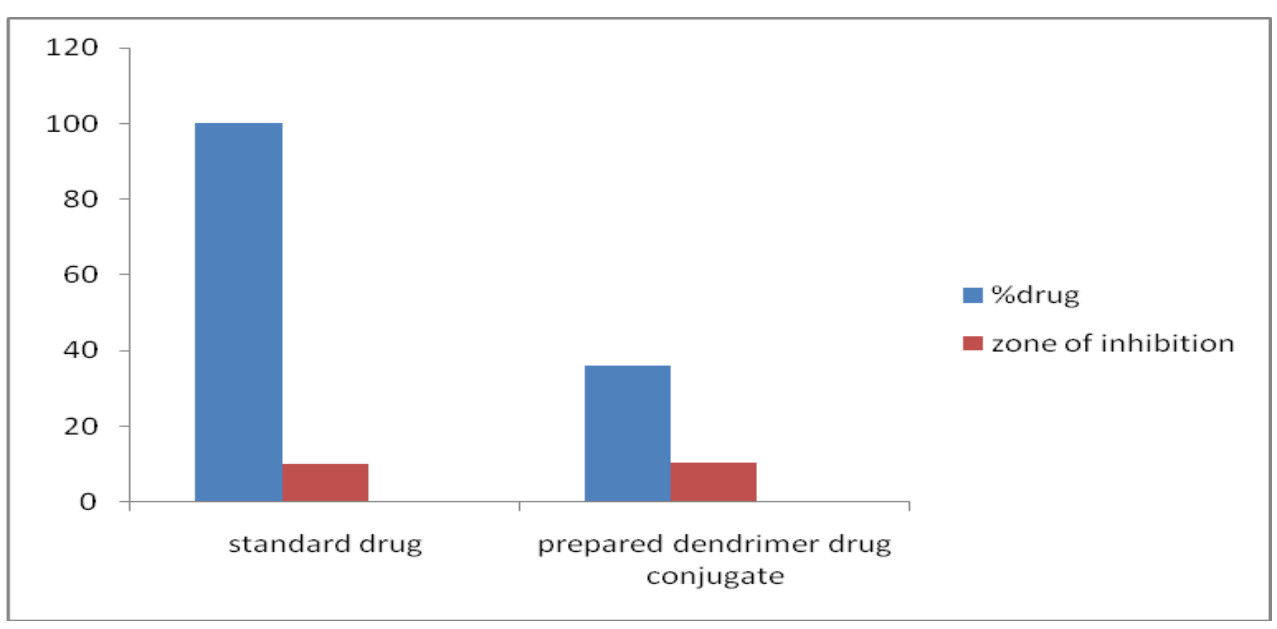

Fig. 3: Graph comparing standard drug and its zone of inhibition and prepared dendrimer drug conjugate and its zone of inhibition in $S$. aureus.

\section{CONCLUSION}

PEG modified triazine based dendrimer was synthesized and characterized by techniques such as FTIR,UV, $\mathrm{H}^{1}$ NMR, Mass. SEM analysis revealed that drug particles is attached and entrapped in synthesized dendrimer. Antibacterial activity shows approximately 2.5 fold increase in activity when compared to drug alone. This might open space for novel and better use of drug salicylic acid and increase in its efficiency with reduced side effect due to low drug concentrations.

\section{ACKNOWLEDGEMENT}

The authors are grateful to Institute of Pharmacy, Vikram University, Ujjain for providing laboratory facility. Authors are thankful for Shree Ji trade international for providing gift samples of chemicals 
required, Standard Calibration laboratory, Indore, SAIF, Punjab University, B.R. Nahta College of Pharmacy, Mandsaur for spectral data.

\section{Conflict of interest}

None declared

\section{REFERENCES}

1. Tomalia DA, Baker H, Dewald J, Hall M, Kallos G, Martin S, Smith P. Polymer journal, 2002; 34(5):132-147.

2. Vögtle F, Richardt G, Werner N. Dendrimer Chemistry Concepts, Synthesis, Properties, Applications. Wiley-Vch Verlag GmbH \& Co. KGaA, Weinheim. 2009; 1-24.

3. Inoue K. Progress in Polymer Science, 2000; 25(4):453-571.

4. Klarjnet B, Bryszewska M. Acta Biochimia Polonica, 2001; 48:199-208.

5. Babu VR, Mallikarjun V, Nikhat SR, Srikanth G. International Journal of Pharmaceutical and Applied Sciences, 2010; 1(1):1-10.

6. Barbara K, Maria B. Acta biochimica polonica, 2001; 48(1):199-208

7. Trivedi V, Patel U, Bhimani B, Daslaniya D, Patel $\mathrm{G}$, Vyas B. International Journal of Pharmaceutical Research \& biosciences, 2012; 1(2):1-21.

8. Chow HF, Mong TKK, Nongrum MF, Wan CW. Tetrahedron, 1998; 54(30):8543-8660.

9. Jana S, Gandhi A, Sen KK, Basu SK. Am J Pharm Tech Res, 2012; 2:32-55.

10. Abbasi E, Aval SF, Akbarzadeh A, Milani M, Nasirabadi HT, Joo SW, Koshki KN, Asl RP. Nanoscale Research letters, 2014; 247(9):1-10.

11. Patel RM, Gajjar DG, Patel HN, Patel PM. International Journal of Chemical Sciences \& Application, 2014; 5(3):94-106.
12. Tambe RV, Pakhare SS, Jha MG, Tiwari SS, Rai CR. International Journal of Research \& Review in Pharmacy \& Applied Sciences, 2014; 2(3):513-528.

13. Malik A, Chaudhary S, Garg G, Tomar A. Advances in Biological Research, 2012; 6(4): 165-169.

14. Nanjwade BK, Bechra HM, Derkar GK, Manvi FV, Nanjwade VK. European Journal of Pharmaceutical Sciences, 2009; 38(3):185-196.

15. McNerny DQ, Leroueil PR, Baker JR. Nanomedicine and Nano biotechnology, 2010; 2(3):249-259.

16. Tomalia DA. Progress in Polymer Science, 2005; 30(3):294-324.

17. Boas U, Christensen JB, Heegaard PM. Royal Society of Chemistry. 2006; 1:1-28.

18. Silva JRNP, Menacho FP, Chorilli M. Journal of Pharmacy, 2012; 2(5):23-30.

19. Pourianazar NT, Mutlu P, Gunduz U. Journal of Nanoparticle Research, 2014; 16(4):1-38.

20. Gupta V, Nayak SK. Journal of Applied Pharmaceutical Science. 2015; 5(3):117-122.

21. Namazi H, Adeli M. Biomaterials, 2005; 26(10): 1175-1183.

22. Hui H, Xiao-dong F, Zhong-lin C. Polymer, 2005; 46(22):9514-9522.

23. Yang H, Morris JJ, Lopina ST. Journal of Colloid and Interface Science, 2004; 273(1):148-154.

24. Jevprasesphant R, Penny J, Jalal R, Attwood D, McKeown NB, D'emanuele A. International Journal of Pharmaceutics, 2003; 252(1):263-266.

25. Golshahi P, Pourianazar NT. Hacettepe J. Biol. \& Chem. 2014; 42(4):485-497.

26. Chauhan AS, Diwan PV, Jain NK, Tomalia DA. Biomacromolecules, 2009; 10(5):1195-1202.

27. Labena A, Kabel KI, Farag RK. Materials Science and Engineering: C, 2016; 58:1150-1159.

28. Shrivastava P, Singh R, Shrivastava S. Chemical Papers, 2010; 64(5):592-601. 